\title{
Commentary: Myocardial protection is a process, not
} an event

\author{
Nathaniel B. Langer, MD, MSc, and Gus J. Vlahakes, MD
}

\author{
From the Department of Surgery, Harvard Medical School, Boston, Mass; and Massachusetts General Hospital, \\ Boston, Mass. \\ Disclosures: Authors have nothing to disclose with regard to commercial support. \\ Received for publication Sept 23, 2019; revisions received Sept 23, 2019; accepted for publication Sept 24, 2019; \\ available ahead of print Sept 30, 2019. \\ Address for reprints: Gus J. Vlahakes, MD, Division of Cardiac Surgery, Massachusetts General Hospital, 55 Fruit \\ St, COX 630, Boston, MA 02114-2696 (E-mail: vlahakes.gus@mgh.harvard.edu). \\ J Thorac Cardiovasc Surg 2020;160:1488-9 \\ $0022-5223 / \$ 36.00$ \\ Copyright $(2019$ by The American Association for Thoracic Surgery \\ https://doi.org/10.1016/j.jtcvs.2019.09.090
}

The study by Timek and colleagues ${ }^{1}$ in this issue of the Journal is the most recent addition to the literature on myocardial protection in adult patients. Dr Pedro del Nido's cardioplegia formulation has made a major contribution to pediatric cardiac surgery. ${ }^{2}$ Because of this success, it continues to gain a greater and greater foothold in adult cardiac surgery; however, its broad adoption remains controversial. The current publication of Timek and colleagues ${ }^{1}$ is another contribution supporting its application, but it must be interpreted with certain caveats.

The advent of myocardial protection, heralded by the landmark contribution of Gay and Ebert, ${ }^{3}$ revolutionized cardiac surgery, making significant improvement in outcomes, allowing more complex surgeries to be done, and allowing surgeons to take the needed time to take trainees through operations. ${ }^{4}$ Irrespective of the formulation used, the basic principles of myocardial protection remain constant: delivery to the entire heart; complete, sustained electromechanical arrest; cooling; and buffering capacity. These principles have not changed and continue to be the underpinning of any myocardial protection method. Traditional cold blood cardioplegia achieves this, but repeated dosing is needed, especially for crossclamp times that exceed an hour, potentially interrupting the flow of the surgical steps in progress.

Multiple studies, including single-institution series, meta-analyses, and a prospective, randomized trial, have shown the relative safety and efficacy of del Nido cardioplegia in adult patients with both valve and coronary disease. ${ }^{5-7}$ Proposed advantages include shorter crossclamp times, smaller volume administration, and even superior myocardial protection. Timek and colleagues ${ }^{1}$ do not report significant advantages with del Nido cardioplegia, but they did find noninferior myocardial protection and overall postoperative outcomes.

The study of Timek and colleagues ${ }^{1}$ must be interpreted keeping in mind that the crossclamp times were not inordinately long. The issue of more complex cases requiring

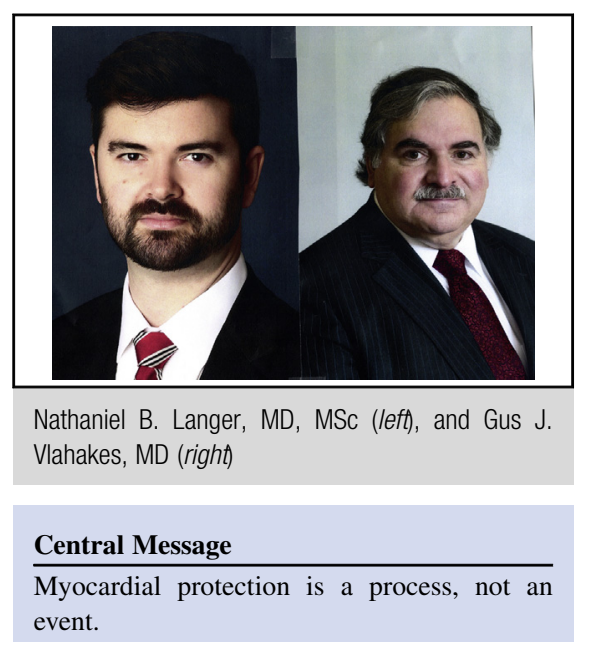

See Article page 1479 . extended crossclamp times, however, remains in question vis-à-vis the applicability of del Nido cardioplegia with long dosing intervals.

One advantage of del Nido cardioplegia may be its superior ability to produce uninterrupted, dense electromechanical arrest, including suppression of micromotion not evident on simple electrocardiographic leads. Thus, extended crossclamp times well beyond those used in this study still require enough repetitive dosing to maintain adequate protection, particularly of the abnormal ventricle. Evidenced-based dosing intervals do not yet exist.

If the literature supports its use, and del Nido cardioplegia streamlines the flow of procedures, then why has it not been more widely adopted? We believe that this is likely due to individual surgeon comfort and to concern regarding how del Nido cardioplegia might perform during extended crossclamp periods. The available studies, including this study, do not include enough patients with long crossclamp times. Caution must therefore be taken in adopting its conclusions for cases requiring extended crossclamp times.

The study reported by Timek and colleagues ${ }^{1}$ is further evidence that single-dose del Nido cardioplegia is safe for revascularization operations conducted with the crossclamp times in this study. Timek and colleagues ${ }^{1}$ acknowledge that they do not address the major remaining question, however, which is how best to protect the heart for extended periods. Until that question has been answered, the debate will continue. 


\section{References}

1. Timek TA, Beute T, Robinson JA, Zalizadeh D, Mater R, Parker JL, et al. Del Nido cardioplegia in isolated adult coronary artery bypass surgery. J Thorac Cardiovasc Surg. 2020;160:1479-85.e5.

2. Matte GS, del Nido PJ. History and use of del Nido cardioplegia solution at Boston Children's Hospital. J Extra Corpor Technol. 2012;44:98-103.

3. Gay WA Jr, Ebert PA. Functional, metabolic, and morphologic effects of potassium-induced cardioplegia. Surgery. 1973;74:284-90.

4. Bloom JP, Heng E, Auchincloss HG, Melnitchouk SI, D'Alessandro DA, Villavicencio MA, et al. Cardiac surgery trainees as "skin-to-skin" operating surgeons: midterm outcomes. Ann Thorac Surg. 2019;108:262-7.

5. Ad N, Holmes SD, Massimiano PS, Rongione AJ, Fornaresio LM, Fitzgerald D The use of del Nido cardioplegia in adult cardiac surgery: a prospective randomized trial. J Thorac Cardiovasc Surg. 2018;55:1011-8.

6. Mick SL, Robich MP, Houghtaling PL, Gillinov AM, Soltesz EG, Johnston DR, et al. del Nido versus Buckberg cardioplegia in adult isolated valve surgery. $J$ Thorac Cardiovasc Surg. 2015;149:626-34.

7. Yerebakan H, Sorabella RA, Najjar M, Castillero E, Mongero L, Beck J, et al. Del Nido cardioplegia can be safely administered in high-risk coronary artery bypass grafting surgery after acute myocardial infarction: a propensity matched comparison. J Cardiothorac Surg. 2014;9:141. 